\title{
Service Navigators in the Workforce: An ethical framework for practice
}

Jennifer Donovan, Ralph Hampson, Marie Connolly

University of Melbourne - Social Work, 161 Barry Street, Carlton, Victoria 3010, Australia

Correspondence: jennifer.donovan@unimelb.edu.au

\section{Abstract}

Aim and Context: This paper explores the current growth of service navigators in complex health and human services and details the development of the Service Navigation Relational Autonomy Framework as a guide to assist practitioners and managers implementing this role.

Approach: The framework was developed using a research into action process. The threestage process included knowledge inquiry: bringing together existing knowledge in practice fields and research; knowledge synthesis: debate and exchange of practitioner insights and messages from research; and knowledge framework: framework creation based on the key elements of evidenceinformed best practice.

Main Findings: The framework centres on four practice domains: reinforcing ethical practices; fostering self-determination; supporting transitions and wellbeing; and mobilising service systems. It incorporates the concept of relational autonomy as a foundation for navigator practice by recognising the nature of relationships and power dynamics in the provision of care, and the central importance of self-determination.

Conclusion A navigation framework is critical for practice guidance and to ensure service navigators and organisations have the capacity to meet the needs of service users and their families.

The framework presented in this paper seeks to encourage debate about service navigation, its implementation, and its future in health and human service organisations.

Keywords: navigation, service navigator, personalisation, relational autonomy, framework, self-determination, advocacy 


\section{INTRODUCTION}

One of the most significant policy directions impacting, disability, health and aged care is the growing emphasis on service personalisation and individual responsibility. At the core of initiatives such as My Aged Care and the NDIS in Australia, is the recognition that service users are partners, rather than grateful recipients of care, and that they are key to determining the services they need. [1, 2] However, requiring individuals to navigate multiple primary, residential and acute services, raises a pressing issue for both system users and service providers. In the context of an increasingly complex and fractured service context, individuals can find systems bewildering, often leaving them lost, confused and unsupported. Likewise, service providers must adjust to market conditions where funding is determined by the choices of consumers, who may be ill-informed about the choices available to them and the quality of services on offer. Service fragmentation has been identified as an important antecedent in the evolution of the role of service navigator which better enables people to understand and work with this complexity, and to support their informed decision-making. [3] Service navigator roles are now becoming increasingly common in areas such as chronic health and oncology [4, 5], primary care [3], disability, and in the recent Tune Review of aged care services in Australia, a key recommendation is that service navigators be provided to support individuals and families. [1]

While the role of service navigation is increasingly visible across health and human services, there is relatively little research to guide practice. In support of the role, research does suggest that the development of the role is an indication of unmet need, particularly in the context of access to healthcare. [3] Further, there are indications that navigation services can help to reduce healthcare disparities [6], and can have a positive impact on health outcomes. [7] In the context of laynavigators, it has been suggested that practical support can also be provided by navigators where patients live with chronic conditions and are beset by social challenges. [8] Relevant to the development of policy and practice frameworks, three components of 'ideal' navigation practice have been identified in the literature reinforcing the importance of: engaging well with families; focusing on more nuanced resource matching; and compassionate navigator persistence when service options are not well enough aligned with need. [9]

In this context of consumer choice and selfdetermination, the growing need for service navigation raises some important questions: What does the service navigation role involve? Who should perform the role? How can consumers be assured of the quality and competency of the service provided? This paper answers some of these questions and proposes an approach to service navigation that supports consumer choice and the ethical mobilisation of services to meet their needs, concerns and aspirations. The Service Navigation Relational Autonomy Framework (SNAF) is a conceptual framework that has its foundations in concepts such as health literacy and patient empowerment, and builds upon the existing patient navigation work in health and social care. This paper describes the development of the SNAF, its core elements and the implications for its use in health and human services.

\section{METHODS - the development of the framework}

Knowledge informed practice frameworks are being developed across a wide range of 
practice areas, integrating research, practice theory, and ethical principles in accessible ways for practitioners. [10] The SNAF was developed using an iterative, practice framework development approach, modelled on this work, particularly in the child protection and family violence areas. [11] The development process began with a phase of knowledge inquiry starting a literature review that brought together existing knowledge in practice fields and related theories focused on autonomy, empowerment and health literacy. Practitioners and researchers then came together in a knowledge synthesis where practitioner insights and messages from research were debated and exchanged. This involved a process of selective reduction and conceptual specification that was then used to create a scaffolding of ideas in the form of the SNAF conceptual knowledge framework, identifying key elements of evidence-informed best practice in an accessible format for practitioners (figure 2 ).

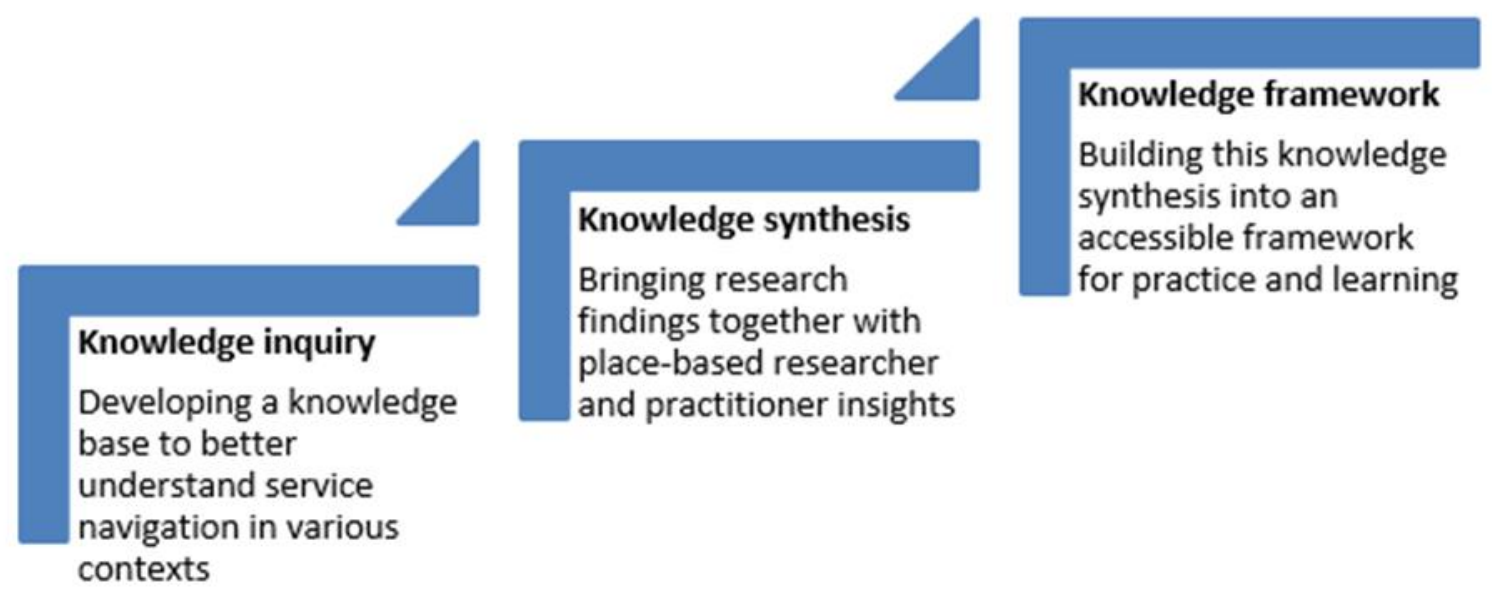

Figure 1: The research into action process

Source: adapted from Connolly, Healy \& Humphreys. [11]

The initial knowledge inquiry stage found that the term navigator has been used across a variety of health-related areas. $[4,5,12]$ These roles focused on aiding service users in complex and fragmented health, disability or aged care systems, where personal and systemic barriers impacted access and choice. It also identified the following key principles for navigation practice $[5,12,13]$ :

- Navigation is patient/client-centred, consumer driven, and equity informed
- Navigation integrates fragmented systems, making them transparent for service users

- It supports consumer choice and eliminates barriers

- Clear navigation roles and responsibilities that are ethically informed

- $\quad$ Support for cost effective navigation services

- Incorporating a spectrum of navigation roles across a diversity of disciplines 
These principles were considered within theoretical paradigms and practices related to patient/client autonomy and empowerment, capacity to "derive meaning from available information and to use that information to exercise greater control of and responsibility for his or her own health" $[14, p 6]$, and patient/service user empowerment, defined as "the patient's participation as an autonomous actor taking increased responsibility for and a more active role in decision making regarding his or her health" [14, p5], have been brought together in the SNAF to advance service provision in the context of self-determination, education and informed choice, and the support of care and wellbeing.

Both the knowledge inquiry phase and the workshops with practitioners also highlighted the importance of a relational rather than individual view of autonomy. Research in both health and aged care $[15,16]$ has highlighted the role of families and agencies in decisionmaking, alongside ethical concerns relating to power and influence. Relational autonomy acknowledges that all individual decisionmaking is conducted in a relational and social context from which the individual cannot be separated. [17] For example, while a young person in palliative care may seek support to make autonomous decisions, it is likely that they do so with a family context and the power dynamics of this context will be a factor in any autonomous decision-making they undertake. Relational autonomy is therefore integrated into the framework as central to the navigator role, focusing understandings of how these factors and dynamics influence selfdetermination.

This material was synthesised through consultations with researchers and and health literacy. Health literacy, defined as the service user's

practitioners leading to the creation of the key domains of the framework. Bringing together research, ethical principles and practitioner experience, enabled the framework to uphold the autonomy and self-determination that is envisioned by policy intent, while also acknowledging and negotiating the practical realities of power, complexity, relationships, interdependency and decision-making in the provision of services.

\section{The Service Navigation Relational Autonomy Framework}

The SNAF is a high-level framework that clarifies the service navigator role through the identification of four key domains that are essential to navigator practice within the context of contemporary patient/client centred service delivery: the reinforcement of ethical practices; fostering self-determination; supporting transitions and wellbeing; and mobilizing service systems. These four, discussed in more detail below, cross fields of practice and can be used to inform more specific practice guidance in areas such as disability, aged care, health and mental health. Each domain has a set of guiding trigger questions (Figure 2) that encourage practitioners to explore particularly important, or contentious areas of practice that were identified in the knowledge inquiry and knowledge synthesis phases of the framework development. In the spirit of the relational autonomy upon which the framework is based, it transparently sets out the critical elements of the service navigator role in ways that are sensitive to power dynamics, supportive of service user decision-making, and accessible to all parties. 


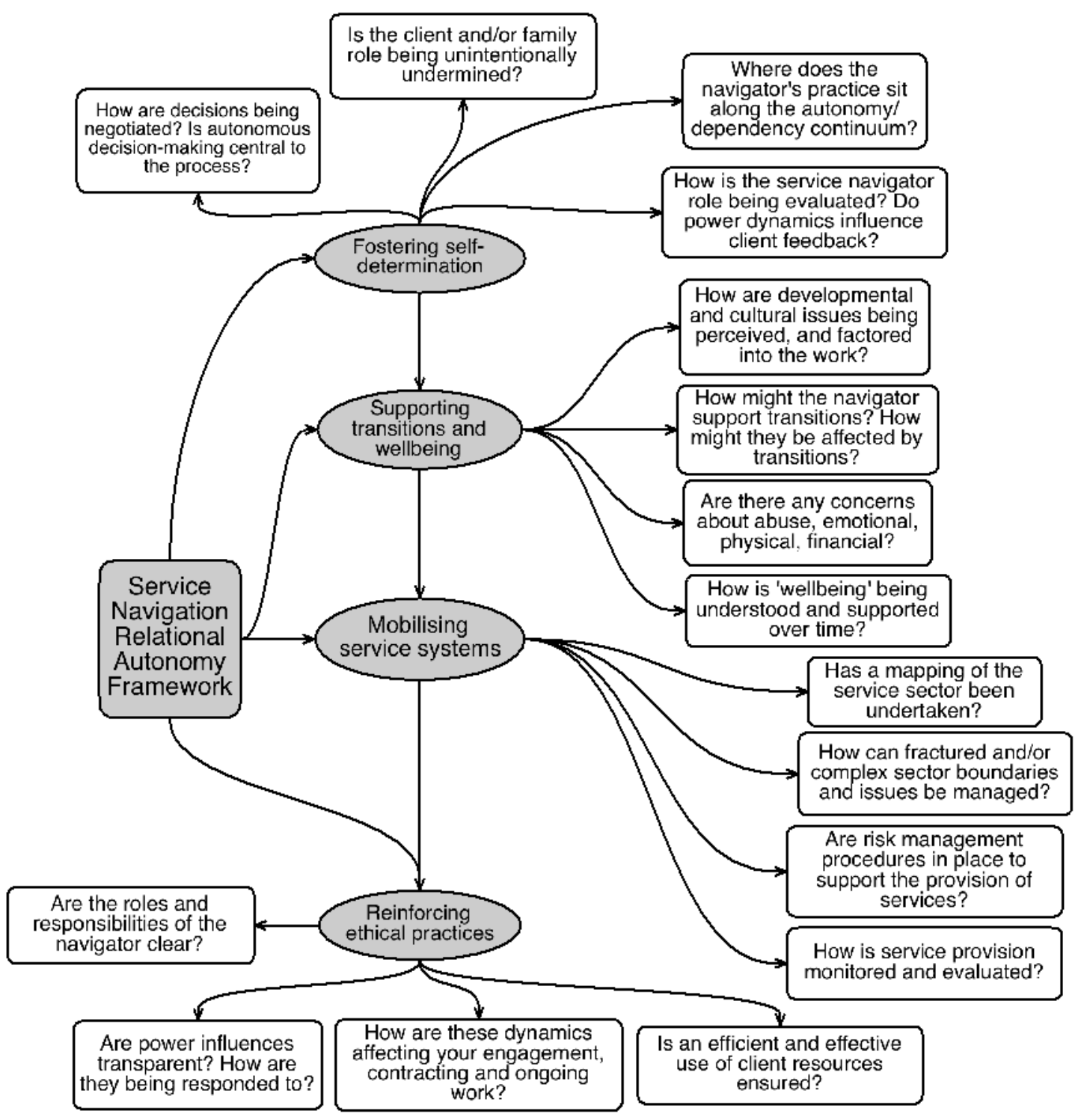

Figure 2: The Service Navigation Relational Autonomy Framework (SNAF)

\section{Fostering self-determination}

This domain guides service navigators to consider factors in relation to selfdetermination, such as autonomous decisionmaking and how the role of family and/or social networks are engaged within this context. The navigator's role is complex here as it has the potential to 'take charge' rather than enable service user self-determination.
The synthetisation process suggested that the navigation role can be undertaken by several professions such as social workers, nurse coordinators or case managers. $[18,19]$ Not all these professions necessarily position serviceuser agency at the forefront of practice and professionals undertaking a service navigation role need to fully appreciate that the emphasis on client autonomy is what distinguishes the role. Professional practice can sit across a continuum in terms of the degree to which it 
supports client autonomy. Connolly and Morris's continuum of a service user-driven to professionally-driven practice [20], illustrates this emphasis and the degree to which a service user may be dependent upon the worker (Figure 3). Service navigation under this framework is firmly positioned at the service user-driven end of the continuum.

\begin{tabular}{|c|c|c|c|}
\hline $\begin{array}{l}\text { The service user contracts } \\
\text { the assessment, and } \\
\text { makes decisions based on } \\
\text { service preference. Service } \\
\text { user evaluates the service } \\
\text { provision and its } \\
\text { continuance over time }\end{array}$ & $\begin{array}{l}\text { Client-centred processes } \\
\text { involve professionals as } \\
\text { important contributors } \\
\text { within a shared decision } \\
\text { making and service } \\
\text { planning context }\end{array}$ & $\begin{array}{l}\text { Professionals determine } \\
\text { who will be involved in } \\
\text { decision making and the } \\
\text { service user is consulted } \\
\text { on the development of the } \\
\text { service plan }\end{array}$ & $\begin{array}{l}\text { Professionally determined } \\
\text { assessment and decision } \\
\text { making. Professionals } \\
\text { decide what is best for the } \\
\text { service user and presents a } \\
\text { service plan to them. }\end{array}$ \\
\hline $\begin{array}{c}\text { Service user-driven } \\
\text { practice }\end{array}$ & \multicolumn{2}{|c|}{ Degree of dependency on professional } & $\begin{array}{c}\text { Professionally-driven } \\
\text { practice }\end{array}$ \\
\hline
\end{tabular}

Figure 3: Autonomy/dependency continuum

Source: adapted from Connolly \& Morris [20, p.73]

Fostering self-determination in these roles, however, will also include negotiating the influence and advice provided by family relationships and other informal networks of support. Navigators may step in where family support is not available, but the role of the navigator is nevertheless to strengthen these supports rather than replacing them. Organisations and navigators need to build a partnership with service users based on a clear understanding of roles and boundaries and how the service will be evaluated and monitored.

\section{Supporting transitions and wellbeing}

Understanding who the service user is, their context, needs and priorities, is essential to providing a tailored navigation service. Other models of navigation allude to understandings of 'client complexity'. [13] Through the synthesis process in developing the SNAF cultural contexts, social support, lifestyle and life course transitions, including adverse life events, have been emphasised as they are critically important to support service user goals and aspirations. Issues across the life course and the significance of life transitions are particularly important when planning service support. [21] For older people for example, self-determination often equates to wellbeing and independence, but this is often dependent on family support networks. [22] Transitions in the life course also represent points at which the navigator will need to negotiate differing views and influences on the service user's decision-making and definitions 
of wellbeing. For example, at the end of life, families and individuals can often have differing views about the level of care required. [23] The navigator needs to negotiate these periods so that a user's personal definition of wellbeing remains central to decision making and navigation practice.

\section{Mobilizing Service Systems}

This domain draws on the tasks outlined in existing research around sector mapping and system boundaries $[2,12,13]$ but also focuses on risk assessment, risk management, and service evaluation. Service navigators require an in-depth understanding of what systems offer, where and to whom, as well as the complexity of how systems interact and overlap (Figure 4). Often multiple systems do not work effectively with each other, complicating service user experience, and the service navigator needs to help to make sense

\section{Core System}

(eg, aged care or chronic health)
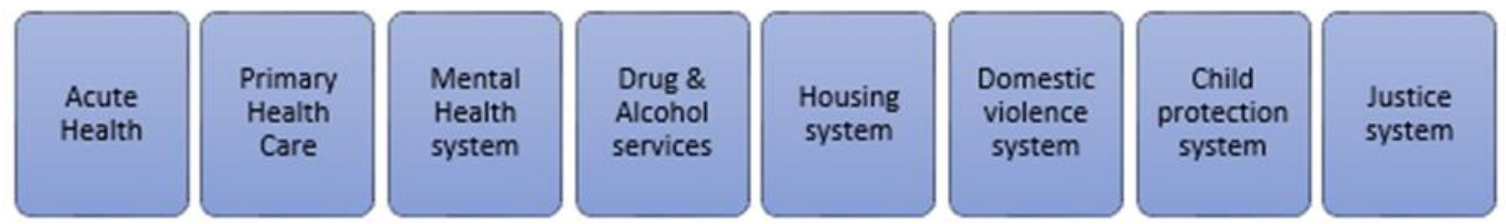

\section{Service Navigation Tasks}

Figure 4: Intersecting systems

The 'mobilising services' domain draws attention to risk assessment and risk management. Working within this framework navigators need to be cognisant of the physical, emotional, legal and organisational risks when clients interact with service systems. For example, an older person may want to continue driving (self-determination and autonomy) but if there is significant risk of harm to themselves or others (incapacity), then risks and responsibilities need to be considered without undermining client autonomy. Understanding the line between risks that are reasonable for an individual to take and those that are unreasonable will be an essential consideration in this work.

\section{Reinforcing ethical practices}

While tasks were clearly identified in the literature on service navigation, the ethical basis upon which navigators' base decisionmaking was less evident. In defining ethical navigation practice, the framework also considers the execution of the navigation role: clarifying roles and responsibilities; transparency; and efficient and effective use of resources. In defining ethical navigation practice, the framework considers the 
execution of the navigation role: clarifying roles and responsibilities; transparency; and efficient and effective use of resources. This domain also focuses on relational autonomy and the importance of power influences.

Power dynamics exist across all human service systems [25], and they can positively or negatively influence outcomes. Understanding power dynamics and undertaking 'powersensitive practice' $[26$, p126] is critical when working within a relational autonomy framework. Relational autonomy recognises power as a normal part of human interactions. [17] It could also be argued that wellbeing is best supported through the moderation of power dynamics and as such navigators need to understand, with the service user, the power dynamics at play, and consider how these might be responded to.

\section{DISCUSSION}

Demand for navigation services is growing and organisations will need to prepare for these changes. The Tune Review [1] has foreshadowed the need for such roles and there is growing expectation from service users that they will be active and autonomous partners in their relationship with services. While this place the navigator in an advocacy role, is not intrinsically linked to any one profession or occupation. Rather, it is interdisciplinary in nature - nurses, primary and allied health professionals, as well as human service workers, social workers and those with peer or consumer backgrounds have already taken up such roles in the health sector. [24] These disciplines already demonstrate the capacity to work between systems, to negotiate within and beyond their own services and to be client-centred in their approaches. Working within a relational autonomy framework is nevertheless likely to present challenges for some disciplines. Social work writers, for example, have already cautioned work with individualised systems which are perceived to be at odds with that professions own ethical and practice standards. [18] We consider that service navigation is best able, nevertheless, to meet the needs of clients if it is developed in response to client and system contexts rather than being reactive to professional or disciplinary constraints. Navigators will draw on many of the skills developed in the broader interdisciplinary mix of human services, reinforcing the potential for service navigation to become a role on its own right, rather than connected to an existing professional context.

The services provided by service navigators do come at a cost, be it privately or publicly funded, and as such there is an obligation to ensure there is commensurate value, quality and accountability. Ethical issues sit at the heart of this and, we would argue, at every stage of the navigator's practice. There is a danger, however, with the increasingly influential social policy movement toward selfdetermined care, that a lack of an ethical framework guiding navigation practice will undermine the very principles of selfdetermination that personalised systems seek to advance. Recognising that service navigation potentially occurs across a range professional context, and may be undertaken by peers, volunteers or professionals, the SNAF clarifies the expectations of the role so that service users can be assured of the quality and competency of the service provided.

\section{CONCLUSION}

Service navigation roles are becoming central to the effective working of personalised care 
within complex service systems, and are being adopted in health, aged care and disability. The SNAF provides a first step in recognising and clarifying the difference in role that Service Navigation presents, offering an accessible frame to guide practice. Identifying key areas that are important to ethical practice within a complex relational context, it provides organisations and individuals with a clear

\section{Reference}

1. Tune D. Legislated review of aged-care 2017. Canberra: Department of Health; 2017.

2. Warr D, Dickenson H, Olney S. Choice control and the NDIS. Melbourne: University of Melbourne; 2017.

3. Carter N, Valaitis RK, Lam A, Feather J, Nicholl J, Cleghorn L. Navigation delivery models and roles of navigators in primary care: A scoping literature review. BMC Health Services Research 2018; 18:96.

4. Manderson B, McMurray J, Piraino E and Stolee P. Navigation roles support chronically ill older adults through healthcare transitions: a systematic review of the literature. Health and Social Care in the Community 2012; 20:113-127.

5. Stewart $M$, Rodriguez R. Patient navigation in oncology. In: Christ G, Messer C and Behar L. Handbook of Oncology Social Work. New York: Oxford University Press; 2015.

6. Freund K, Paskett E, Corle D, Snyder F, Calhoun E, Dudley $D$. Patient navigation and timeliness of diagnostic evaluation: results from the patient navigation research programme. Cancer Epidemiol Biomarkers Prev 2011; 20(Suppl 1): PL06-02

7. The Centre for Health Affairs. The emerging field of patient navigation: a golden opportunity to improve healthcare. Cleveland: The Centre for Health Affairs; 2012.

8. Doolan-Noble F, Smith D, Gauld R, Waters DL, Cooke $A K$, Reriti $\mathrm{H}$. Evolution of a health navigator model of care within a primary care setting: A case study. Australian Health Review 2013; 37:523-528.

9. Markoulakis R, Weingust S, Foot J, Levitt A. The Family Navigation Project: An innovation in working with families to match mental health services with their youth's needs. Canadian Journal of Community Mental Health 2016; 35:63-66

10. Connolly M, Healy K. Social work practice theories and frameworks. Chapter 2 in Social Work Contexts and practice 4th edition. Melbourne: Oxford University Press; 2017.

11. Connolly M, Healey L \& Humphreys C. The collaborative practice framework for child protection understanding of the knowledge and skills required to undertake the service navigation role well. As with all new models, further research and evaluation will be required to determine its ongoing relevance and efficacy in creating meaningful partnerships between clients, service navigators and the systems they are a part of. and specialist domestic and family violence services: Key findings and future directions. Compass: Research to policy and practice, issue 3 , June 2017. Canberra: ANROWS; 2017.

12. Freeman $\mathrm{H}$. The origin, evolution and principles of patient navigation. Cancer Epidemiology, Biomarkers \& Prevention 2012; 21:1614-1617.

13. Valaitikis R. Implementation and maintenance of patient navigation programs linking primary care with community-based health and social services: a scoping literature review. BMC Health Services Research BMC series 2017; 17:116.

14. Schulz P and Nakamoto K. Health literacy and patient empowerment in health communication: The importance of separating the conjoined twins. Patient Education and Counselling 2013; 90:4-11.

15. Ells $\mathrm{C}$, Hunt $\mathrm{M}$ and Chamber-Evans J. Relational autonomy as an essential component of patient-centred care. International Journal of Feminist Approaches to Bioethics 2011; 4:79-101.

16. Perkins $\mathrm{M}$, Ball $\mathrm{M}$, Wittington $\mathrm{F}$ and Hollingsworth $\mathrm{C}$. Relational autonomy in assisted living: a focus on diverse care settings for older adults. Journal of Aging Studies 2012; 26:214-225.

17. Mackenzie $C$ and Stoljar N. Introduction: Autonomy refigured. In: Mackenzie $\mathrm{C}$ and Stoljar N. Relational autonomy: feminist perspectives on autonomy, agency and the social self. New York: Oxford University Press; 2000.

18. Leece $J$ and Leece D. Personalization: perceptions of the role of social work in a world of brokers and budgets. British Journal of Social Work 2011; 41:204223.

19. Dohan D and Schrag D. Using navigators to improve care of underserved patients: current practices and approaches. Cancer 2005; 104:848-855.

20. Connolly $\mathrm{M}$ and Morris K. Understanding child and family welfare: statutory responses to children at risk. New York: Palgrave Macmillian; 2012.

21. Elder GH. (1985). Perspectives on the life course. In: Elder GH. Life course dynamics: trajectories and 
transitions, 1968-1980. Ithaca, NY: Cornell University Press; 1985.

22. Rodin J and Langer E. Long-term effects of a controlrelevant intervention with the institutionalized aged. Journal of personality and social psychology 1977; 35:897-902.

23. Hopeck $P$ and Harrison T. Reframing, refocusing, referring, reconciling and reflecting: exploring conflict resolution strategies in end-of-life situations. Health Communication 2017; 32:240-246.
24. Meade C, Wells K, Arevalo M, Calcano E, Rivera M, Sarmiento $\mathrm{Y}$, Freeman $\mathrm{H}$ and Roetzheim $\mathrm{R}$. Lay navigator model for impacting cancer health disparities. Journal of cancer education 2014; 29:449-457.

25. Ozanne $E$ and Rose D. The organizational context of human service practice. Melbourne: Palgrave Macmillan; 2013.

26. Beckett C. Essential theory for social work practice. London: Sage; 2006. 